\title{
Dual therapy strategies for COPD: the scientific rationale for LAMA + LABA
}

\author{
This article was published in the following Dove Press journal: \\ International Journal of COPD \\ 15 April 2016 \\ Number of times this article has been viewed
}

\section{Joshua S Cohen' \\ Matthew C Miles ${ }^{2}$ \\ James F Donohue ${ }^{3}$ \\ Jill A Ohar}

'United Lung and Sleep Clinic, Saint Paul, MN, USA; ${ }^{2}$ Department of Internal Medicine, Wake Forest School of Medicine, Winston-Salem, NC, USA ${ }^{3}$ University of North Carolina Chapel Hill, Chapel Hill, NC, USA
Correspondence: Joshua Cohen United Lung and Sleep Clinic, 225 North Smith Avenue Suite 50I, Saint Paul, MN 55I02, USA

$\mathrm{Tel}+\mathrm{I} 6517266200$

Fax + 65| $726620 \mid$

Email joshua.cohen@allina.com

\begin{abstract}
Chronic obstructive pulmonary disease (COPD) is a leading cause of morbidity, mortality, and health care expenditure worldwide. Relaxation of airway smooth muscle with inhaled bronchodilators is the cornerstone of treatment for stable COPD, with inhaled corticosteroids reserved for those with a history of exacerbations. Tiotropium has occupied center stage in COPD treatment for over 10 years and improves lung function, quality of life, exercise endurance, and reduces the risk of COPD exacerbation. Long-acting $\beta_{2}$-agonists (LABAs) improve lung function, reduce dynamic hyperinflation, increase exercise tolerance, health-related quality of life, and reduce acute exacerbation of COPD. The combination of long-acting muscarinic antagonists (LAMAs) and LABAs is thought to leverage different pathways to induce bronchodilation using submaximal drug doses, increasing the benefits and minimizing receptor-specific side effects. Umeclidinium/vilanterol is the first combination of LAMA/LABA to be approved for use in stable COPD in USA and Europe. Additionally, indacaterol/glycopyrronium and aclidinium/formoterol have been approved in Europe and in numerous locations outside USA. Several other agents are in the late stages of development, most of which offer once-daily dosing. The benefits of new LAMA/LABA combinations include improved pulmonary function, dyspnea, and health-related quality of life, and in some cases, reduced exacerbations. These evolving treatments will provide new opportunities and challenges in the management of COPD.
\end{abstract}

Keywords: bronchodilator, fixed-dose combination, chronic bronchitis, emphysema, COPD treatment

\section{Introduction}

Chronic obstructive pulmonary disease (COPD) is a leading cause of suffering and is an increasing burden to patients and society. Mortality due to COPD is projected to increase to become the third most common cause of death worldwide by $2030 .^{1,2}$ The array of available inhaled medications is increasing; a number of new agents are either recently approved or are in late-stage clinical trials. In this paper, we will review the current and emerging evidence for combining long-acting muscarinic antagonists (LAMAs) with long-acting $\beta_{2}$-agonists (LABAs) in COPD.

\section{Pathogenesis}

The pathogenesis of COPD is understood to be an inflammatory response to inhaled particles, the most important of which is tobacco smoke. ${ }^{3}$ Exposure to other respiratory irritants such as burned biomass fuels and vocational dusts are significant risk factors for COPD. ${ }^{4,5}$ In susceptible persons, respiratory irritants precipitate an inflammatory response leading to local inflammation causing pulmonary disease clinically recognized as COPD. The subtypes of chronic bronchitis and emphysema are often described, 
although with a few exceptions, the distinction lacks therapeutic inference. Pathologically, one observes varying degrees of airway narrowing, mucus hypersecretion, and loss of small conducting airways. ${ }^{6}$ Normal pulmonary physiology is substantially altered in COPD such that the small airways $(<2 \mathrm{~mm})$ become the major site of airflow resistance.

These anatomic changes lead to expiratory airflow limitation, air trapping, and ventilation-perfusion mismatch. ${ }^{7}$ Additionally, the loss of elastic recoil and hyperinflation adversely affect thoracic and diaphragmatic mechanics, increasing the work of breathing, and ultimately leading to dynamic hyperinflation. ${ }^{8}$ Hyperinflation is an independent predictor of mortality in COPD. ${ }^{9}$ Treatment with inhaled bronchodilators can reduce hyperinflation, improve dyspnea and increase exercise tolerance. ${ }^{10}$

Spirometry remains the gold standard diagnostic test, and although controversy remains regarding the use of a fixed ratio or lower limit of normal, a reduced $\mathrm{FEV}_{1}$ (forced expiratory volume in the first second)/FVC (forced vital capacity) ratio not fully reversed with bronchodilators is required to confirm a clinical diagnosis. ${ }^{11,12}$ The severity of COPD was previously grouped by airflow limitation, but since 2011, the Global Initiative for Chronic Obstructive Lung Disease (GOLD) report has advised using the Combined COPD Assessment Test (CAT), placing patients into a multidimensional grouping algorithm (A-D) determined by symptoms, breathlessness, and risk of exacerbation. Symptom burden is measured by the CAT score and breathlessness is measured by the modified Medical Research Council dyspnea scale. Risk of exacerbation is determined by exacerbation history in the preceding year and $\mathrm{FEV}_{1}$. Although reduced FEV is independently associated with increased mortality, the association between $\mathrm{FEV}_{1}$ and dyspnea is poor. ${ }^{11}$

\section{Burden}

Broadly speaking, the chronic course of COPD is characterized by dyspnea, exercise limitation, cough, sputum expectoration, and wheezing. These symptoms vary substantially from patient to patient and day to day. The chronic course is punctuated, at least in some individuals, with acute exacerbations of chronic obstructive pulmonary disease (AECOPD). AECOPD are associated with a decreased quality of life (QOL), ${ }^{13}$ a modestly accelerated loss of $\mathrm{FEV}_{1},{ }^{14}$ and increased mortality. Those who are hospitalized for AECOPD are at increased risk of 1 year mortality of at least $18 \% .{ }^{15}$ Furthermore, greater frequency and severity of AECOPD are independently associated with increased mortality. ${ }^{16}$ In a recent report from the ECLIPSE cohort, a greater frequency of exacerbation has been described to be a stable phenotype over time. ${ }^{17}$ Costs associated with COPD are substantial, estimated to be over $\$ 50$ billion, the majority is spent treating acute exacerbations. ${ }^{18}$

Respiratory symptoms, even in smokers, are poor predictors of a diagnosis of COPD, ${ }^{19}$ and up to $50 \%$ of COPD cases are not recognized and treated. In a prevalence study of over 9,000 adults in 12 countries, stage II (moderate) or greater COPD was identified in $10 \%$. This study included both never, former, and active smokers. ${ }^{20}$ Furthermore, Buist et $\mathrm{al}^{20}$ identified stage II or greater COPD in 3\%-11\% in never smokers. A recent report from the ECLIPSE study showed that $22 \%$ of patients with stage II COPD experienced frequent exacerbations, ${ }^{17}$ indicating a higher risk phenotype.

Increasingly, COPD is recognized to be associated with other illnesses remote to the lung itself. In addition to the apparent increase in lung cancer observed in smokers, we now recognize that patients with COPD have a substantial burden of cardiovascular, metabolic, musculoskeletal, and other diseases. ${ }^{21}$ These diseases must be recognized in clinical practice in order to optimize the safety of treatments and most directly address the mechanism of the patient's symptoms and physiology. For example, dyspnea or fatigue may be mediated by dynamic hyperinflation and poor muscle function in a given individual. Despite improvements in $\mathrm{FEV}_{1}$ and inspiratory capacity, dyspnea due to muscle weakness will be unresponsive to optimal bronchodilation.

\section{Overview of treatment}

Inhaled bronchodilators are the central therapeutic agents for COPD. Comprehensive treatment includes numerous other measures guided by the needs and goals of the specific patient, the most critical of which are smoking prevention and cessation. The array of other treatments includes pulmonary rehabilitation, infection prevention with immunizations, inhaled corticosteroids (ICS), and adjunctive medications, such as phosphodiesterase-4 inhibitors (theophylline or roflumilast), macrolides, and oxygen. Lung volume reduction and lung transplantation are surgical options in appropriate patients. ${ }^{11,12}$

Airway tone is controlled by both the sympathetic and parasympathetic nervous systems. These mechanisms interact and may potentiate each other, and are employed alone or in combination therapeutically. Relaxation of airway smooth muscle is caused by blockade of acetylcholine activity at the receptor (muscarinic antagonist) or stimulation of the G protein-coupled receptor ( $\beta$-agonist). ${ }^{22}$ The resting airway tone is mediated by the parasympathetic system, which is delivered to the airways via the vagus nerve. Acetylcholine 
Table I Regulatory status of fixed dose LAMA/LABA combinations

\begin{tabular}{|c|c|c|c|}
\hline Drug & Trade name & Approved dose & Approval status \\
\hline \multirow[t]{2}{*}{ Umeclidinium/vilanterol } & Anoro ${ }^{\mathrm{TM}}$ & $62.5 / 25 \mu \mathrm{g}$ once daily (USA) & FDA approved 2013 \\
\hline & Ellipta $^{\circledR}$ & $55 / 22 \mu \mathrm{g}$ once daily (Europe) & EMA positive opinion 2014 \\
\hline \multirow[t]{3}{*}{ QVAI49 } & Ultibro ${ }^{\circledR}$ & $85 / 43 \mu \mathrm{g}$ once daily - Europe, & EMA positive opinion 2013 , \\
\hline & Breezhaler ${ }^{\circledR}$ & Canada, Japan, Latin America & FDA application complete \\
\hline & & & for $27.5 / 12.5 \mu \mathrm{g}$ twice daily \\
\hline Aclidinium/formoterol & Brimica $^{\circledR}$, Genuair $^{\circledR}$ & $340 / / 2 \mu g$ twice daily & EMA positive opinion 2014 \\
\hline Tiotropium/olodaterol & Stiolto ${ }^{\mathrm{TM}}$, Respimat $^{\circledR}$ & $2.5 / 2.5 \mu \mathrm{g}$ two puffs once daily & FDA approved 2015 \\
\hline Glycopyrronium/formoterol & - & - & - \\
\hline
\end{tabular}

Abbreviations: EMA, European Medicines Agency; FDA, US Food and Drug Administration; LABAs, long-acting $\beta_{2}$-agonists; LAMAs, long-acting muscarinic antagonists; QVAI49, indacaterol/glycopyrronium.

receptors (AChRs) have been identified in the large and small airways, glandular and epithelial cells, as well as multiple other cells of the lung. Stimulation of the AChR causes increased tone in airway smooth muscle, and blockade of AChR reduces airway tone. Direct sympathetic innervation has been identified in submucosal tissue, lung vasculature, and inflammatory cells, but is nearly absent in airway smooth muscle cells. Although $\beta$-adrenergic receptors can be identified in the airway smooth muscle cell, innate physiologic stimulation of the airway smooth muscle $\beta$-adrenergic receptors requires circulating sympathetic mediators. Currently, inhaled $\beta$-agonists are used therapeutically to stimulate this receptor to cause bronchodilation. This method of inhaled topical delivery reduces side effects when compared to intravenous treatment with $\beta$-agonists.

Anticholinergic drugs in the form of smoked alkaloids were among the first effective treatments for asthma, ${ }^{23}$ and in the early 19th century, the smoking of asthma cigarettes containing Datura ferox or Datura stramonium was widely popular. In the mid-20th century, parenteral muscarinic antagonists and $\beta$-agonists were used for acute attacks of asthma. ${ }^{24}$ Parenteral delivery was associated with side effects and a short duration of benefit. As such, subsequent work has both optimized the receptor specificity and the duration of action. The LAMA, tiotropium (TIO), was approved by the US Food and Drug Administration (FDA) in 2004 and has occupied a central role in the management of COPD for the last decade. The FDA has approved two other LAMAs, aclidinium (ACL) in 2012, ${ }^{25}$ and umeclidinium (UMEC) in $2014 .{ }^{26}$

$\beta$-agonists were in use in Chinese medicine for millennia in the form of ephedra. Developments in the mid-20th century yielded compounds that specifically target the $\beta_{2}$-adrenergic receptor, reducing the side effects from $\beta_{1}$-agonists. ${ }^{22}$ Further work yielded the LABAs, salmeterol, and formoterol (FOR). More recent agents such as indacaterol have been developed which last 24 hours, providing new prospects for once-daily combination therapy in fixed combinations. LAMA/LABA combinations currently approved or in development are listed in Table 1.

\section{Comments on study outcome measures}

Interpretation of study results is oriented around the unique perspective of the stakeholder, the relative value of a given outcome may differ from the view of the patient, physician, third party payer, etc. ${ }^{27}$ The informed viewpoint of the patient should remain central to framing the relative benefits and costs of treatments. Study endpoints are optimally interpreted using the minimal clinically important difference (MCID) rather than statistical differences alone. These endpoints have been reviewed recently and are summarized in Table 2.27-30 The MCID has several limitations that are important to consider. First, the MCID cannot be verified against objective standards and is thus dependent on subjective value judgments. Second, some endpoints are affected by time, and bias may be introduced by the duration of a trial. ${ }^{29}$ The interval benefit of a combination therapy is unlikely to be as great as the benefit of adding a single agent to placebo (PCBO). Jones et $\mathrm{l}^{29}$ propose that the proportion of those meeting the MCID criteria should be compared rather than the group means. The relative worthwhile change using responder analysis has not been established in COPD, and the term "minimal worthwhile incremental advantage" has been proposed. ${ }^{29}$

An ideal therapy in COPD would reduce mortality and dyspnea, increase exercise tolerance, increase QOL, and reduce the frequency and severity of exacerbations and hospitalizations. The cost of maintenance therapies is a critical consideration, both in wealthy and developing countries. Ideal therapies would additionally reduce the overall cost of treating COPD. Reduction in exacerbation frequency has been reported with both FOR and salmeterol, ${ }^{18} \mathrm{TIO},{ }^{31}$ and 
Table 2 Selected outcomes and definition of significant differences

\begin{tabular}{|c|c|c|}
\hline Outcome & MCID & Comments \\
\hline Trough FEV, & $100 \mathrm{~mL}$ & $\begin{array}{l}\text { No MCID established } \\
\text { for AUC, FVC }\end{array}$ \\
\hline $\begin{array}{l}\text { Health-related } \\
\text { quality of life }\end{array}$ & SGRQ: 4 units & $\begin{array}{l}\text { Higher score indicate } \\
\text { poorer health status }\end{array}$ \\
\hline Dyspnea & TDI $\geq$ I unit & - \\
\hline $\begin{array}{l}\text { Rescue medication } \\
\text { use }\end{array}$ & $\begin{array}{l}\text { No validated } \\
\text { MCID }\end{array}$ & - \\
\hline Exacerbations & $\begin{array}{l}\text { I exacerbation/year, } \\
22 \% \text { reduction }\end{array}$ & $\begin{array}{l}\text { Definition of AECOPD } \\
\text { varies. Seasonal variation } \\
\text { in frequency impacts } \\
\text { studies }<12 \text { months }\end{array}$ \\
\hline $\begin{array}{l}\text { Daily respiratory } \\
\text { symptoms }\end{array}$ & E-RS total $>-2$ & $\begin{array}{l}\text { Suggested responder } \\
\text { definition }\end{array}$ \\
\hline
\end{tabular}

Notes: The MCID was developed for comparison between an active treatment and placebo; MCID comparing active treatments is not defined. Copyright (C) 20II. Future Science Ltd. Adapted from Miles MC, Donohue JF, Ohar JA. Combination therapy for COPD: emerging evidence from recent clinical trials. J Clin Invest, 20 I I; I (6):879-890 with permission of Future Science Ltd. ${ }^{27}$ Additional data from Cazzola et al ${ }^{28}$ and Leidy et al. ${ }^{30}$ Abbreviations: AECOPD, acute exacerbation of chronic obstructive pulmonary disease; AUC, area under the curve; E-RS total, EXACT respiratory symptoms total score; $\mathrm{FEV}_{1}$, forced expiratory volume in the first second; FVC, forced vital capacity; MCID, minimal clinically important difference; SGRQ, St George Respiratory Questionnaire; TDI, transition dyspnea index.

fixed combinations of inhaled salmeterol-fluticasone or budesonide-FOR. ${ }^{32,33} \mathrm{We}$ will review the evidence for newer combinations of LAMA/LABA.

\section{Combination of short-acting bronchodilators and approved LAMA/LABAs: an overview}

Multiple lines of evidence support the physiologic rationale, clinical efficacy, and safety of combining anticholinergic and $\beta_{2}$-agonist bronchodilators. The pharmacology of bronchodilators and the scientific rationale for the combination of LAMAs and LABAs has been extensively reviewed by Cazzola et $\mathrm{al}^{22}$ and Cazzola and Molimard. ${ }^{34}$ By leveraging different receptor types at submaximal doses, combination agents may increase therapeutic benefits while minimizing dose-dependent side effects. Pragmatically, consolidating treatments into single devices ought to decrease the complexity of usage, easing the burden on patients who are typically treated for multiple different conditions other than COPD.

The combination of short-acting muscarinic antagonist ipratropium bromide and the short-acting $\beta_{2}$-agonist (SABA) albuterol (ALB) was described in two trials of the inhaler, COMBIVENT, ${ }^{35}$ and the nebulized preparation. ${ }^{36}$ Compared to the single components, ipratropium bromide + ALB provided significant improvements in $\mathrm{FEV}_{1}$ peak, $\mathrm{FEV}_{1}$ area under the curve (AUC), and FVC with a similar safety profile..$^{35}$ The clinical changes noted by the patients and the study teams were not significantly different; however, as the authors note, the baseline symptoms were mild. Further studies demonstrated that the combination of LAMA and LABA in separate devices (free combinations) were beneficial. For example, when compared to salmeterol $50 \mu \mathrm{g}$ twice daily or TIO $18 \mu \mathrm{g}$ daily, the combination of both drugs increased trough $\mathrm{FEV}_{1}(103-125 \mathrm{~mL}, P \leq 0.05), \mathrm{FVC}(171-226 \mathrm{~mL}$, $P \leq 0.05)$, significantly improved dyspnea $(P<0.005)$, and reduced the amount of rescue salbutamol $(P<0.005)$ required, without reducing safety compared to monocomponents. ${ }^{37}$

Combinations of long-acting bronchodilators are recommended for patients who remain symptomatic despite the use of a single long-acting bronchodilator. In patients without exacerbations, the ICS are not typically recommended. Currently, several combination medications are in various stages of development, and clinicians and patients have expanding options in selecting LAMA/LABA combinations. Selected reported outcomes are summarized in Table 3.

\section{The future: LAMA/LABA Umeclidinium/vilanterol}

Umeclidinium/vilanterol (UMEC/VI) is the first fixed LAMA/LABA combination to garner approval by the FDA and has achieved a favorable review from the European Medicines Agency (EMA). It has been approved in Europe at $55 / 22 \mu \mathrm{g}$ dose, in the US at $62.5 / 25 \mu \mathrm{g}$, and is a dry powder inhaler (DPI) dosed one inhalation daily. The reported efficacy of UMEC/VI is summarized in Table 3. A dose ranging study of UMEC identified that once-daily dosing at 62.5 or $125 \mu \mathrm{g}$ was optimal. ${ }^{38} \mathrm{VI}$ doses of 25 or $50 \mu \mathrm{g}$ have been identified to be optimal in terms of increasing $\mathrm{FEV}_{1}$ and had a safety profile similar to PCBO. ${ }^{39}$ When UMEC and VI were administered in combination by the inhaled route, the pharmacokinetics of each component was similar to those observed when each active substance was administered separately. The predispensed dose is $74.2 \mu \mathrm{g}$ equivalent to $62.5 \mu \mathrm{g}$ of UMEC and $25 \mu \mathrm{g}$ of VI. The delivered dose leaving the mouthpiece is UMEC $55 \mu \mathrm{g}$ and VI $22 \mu \mathrm{g}$.

Both are stable when given in combination. The absolute bioavailability of UMEC is $13 \%$ and VI, $27 \%$. As for biotransformation, UMEC is metabolized by the cytochrome P4502D6 (CYP2D6), while VI is metabolized by P4503A4 (CYP3A4). In contrast to indacaterol/glycopyrronium (QVA149), there is an interaction. In order to match the fine particle doses in the combination, the dose of indacaterol was adjusted from 75 to $55 \mu \mathrm{g} .{ }^{40,41}$ Similar considerations are applicable for other combination products. Initial safety studies of a fixed combination of UMEC/VI 500/25 $\mu \mathrm{g}$ once daily vs PCBO for 28 days showed that UMEC/VI did not change 


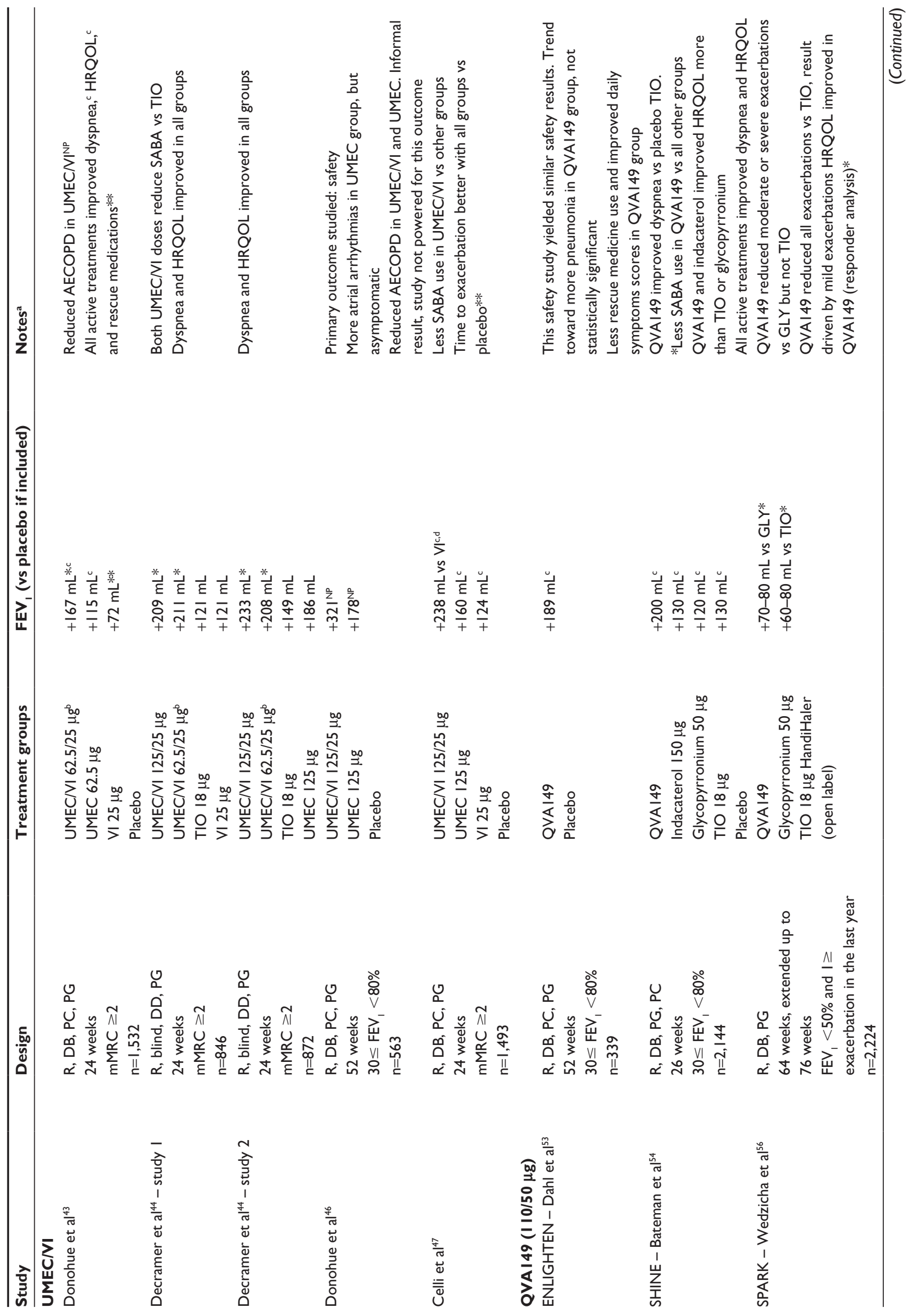




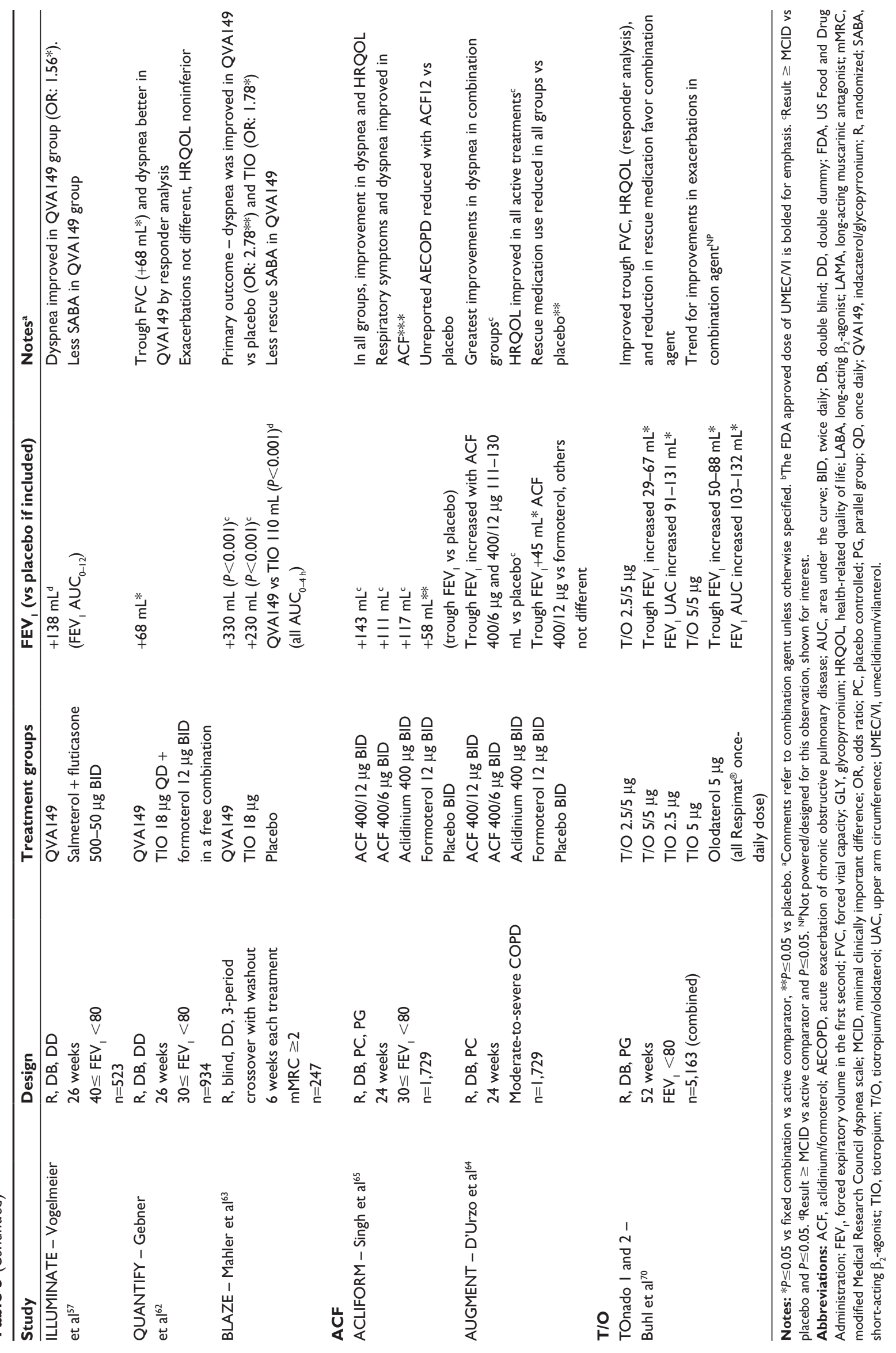


pulse, blood pressure, or the QT interval. The emergence of clinically significant abnormalities in Holter monitors was similar in the PCBO arm and the UMEC/VI arm. ${ }^{42}$ Subsequent trials have investigated doses ranging from UMEC 62.5 to $125 \mu \mathrm{g}$ in a fixed combination with VI $25 \mu \mathrm{g}$.

In the first efficacy trial, UMEC/VI $62.5 / 25 \mu \mathrm{g}$ was compared to UMEC $62.5 \mu \mathrm{g}$, VI $25 \mu \mathrm{g}$, and PCBO over 6 months. ${ }^{43}$ Despite improvements in $\mathrm{FEV}_{1}$ and FVC in the dual therapy arm vs UMEC and VI, dyspnea and QOL were similar in all active treatment groups. Although not designed or powered to study AECOPD, treatment with UMEC/VI but not UMEC or VI resulted in a lower risk of COPD exacerbations with a hazard ratio (HR) of $0.5(P \leq 0.01)$ compared to PCBO. Safety was similar in all groups, and there was a low incidence of anticholinergic symptoms $(<3 \%)$ similar to PCBO. Beta effects were not different in groups treated with VI than PCBO. Interestingly, the UMEC/VI had the lowest withdrawal rate (20\%) compared to PCBO (27\%). Furthermore, $13 \%$ of the PCBO withdrew for lack of efficacy compared to $5 \%$ in the UMEC/VI group.

Decramer et a ${ }^{44}$ reported a paired 24-week trial comparing two doses of UMEC/VI (125/25 and 62.5/25 $\mu \mathrm{g})$ with TIO $18 \mu \mathrm{g}$, UMEC $125 \mu \mathrm{g}$, and VI $25 \mu \mathrm{g}$. Both doses of $\mathrm{UMEC} / \mathrm{VI}$ produced greater improvements in trough $\mathrm{FEV}_{1}$ compared to VI or TIO, but did not improve $\mathrm{FEV}_{1}$ compared to UMEC monotherapy. ${ }^{44}$ In contrast to the improvements in $\mathrm{FEV}_{1}$, symptom scores and health-related quality of life (HRQOL) were similar between groups. Furthermore, the rate of exacerbation was similar over the 6-month study. Safety was similar between groups; however, numerically, more patients in the UMEC/VI groups withdrew from the study. The authors concluded that UMEC/VI is beneficial in that it produced improvements in lung function with similar safety. In an accompanying editorial, the lack of significant difference in symptoms or exacerbations compared to TIO alone was referenced as a call to develop drugs that would impact these patient-centered outcomes, rather than lung function alone. ${ }^{45}$

Two more trials investigating the doses of UMEC/VI $125 / 25 \mu \mathrm{g}$ were reported in 2014 . We will review these studies for evidence of efficacy and safety, although the reader is reminded that the approved dose is $62.5 / 25 \mu \mathrm{g}$ in the US and 55/22 $\mu \mathrm{g}$ in Europe.

The first study of 563 patients reported by Donohue et a $1^{46}$ reported the safety of UMEC/VI 125/25 $\mu \mathrm{g}$ compared to UMEC 125 and PCBO for 1 year. Overall, adverse events and serious adverse events were similar in all groups. UMEC monotherapy caused more atrial arrhythmias on electrocardiogram and Holter monitors, but as these events were asymptomatic, the clinical significance was questioned. Although the study was not designed or powered to detect changes in exacerbation frequency or lung function, the trend in exacerbation deserves mention. Fewer patients had COPD exacerbations in the UMEC/VI (13\%) and UMEC (15\%) groups compared to PCBO (24\%), translating into fewer hospitalizations in the active treatment groups $(6 \%-7 \%)$ vs PCBO (12\%).

In a 6-month study comparing UMEC/VI $125 / 25 \mu \mathrm{g}$ to UMEC $125 \mu \mathrm{g}$, VI $25 \mu \mathrm{g}$, and PCBO, UMEC/VI improved trough $\mathrm{FEV}_{1} 238 \mathrm{~mL}$ vs $\mathrm{PCBO}, 79 \mathrm{~mL}$ vs UMEC, and $114 \mathrm{~mL}$ vs VI ( $P \leq 0.001$ for all). UMEC/VI improved dyspnea and HRQOL more than PCBO or monocomponents, but the improvements were less than the MCIDs. All active treatments lowered the risk of AECOPD with a HR of 0.4-0.5 compared to $\mathrm{PCBO} .{ }^{47}$ The reader is reminded that this trial tested a dose of UMEC/VI that is above the doses approved by the EMA and FDA.

Taken together, UMEC/VI appears to be safe, produces greater improvements in lung function compared to monocomponents, and in some studies reduces the risk of exacerbations. UMEC/VI has not, however, shown dramatic improvements in dyspnea or HRQOL compared to TIO or the components UMEC or VI.

\section{Indacaterol/glycopyrronium}

Indacaterol/glycopyrronium (QVA149) is a DPI containing indacaterol $110 \mu \mathrm{g}$ and glycopyrronium (GLY) $50 \mu \mathrm{g}$ taken once daily, marketed as Ultibro Breezhaler (Novartis Pharmaceuticals UK Ltd, Surrey, UK). The EMA recommended that Ultibro Breezhaler be granted marketing authorization in $2013 ;{ }^{48}$ Novartis completed an application to the FDA. ${ }^{49}$ The component indacaterol has been approved by EMA and FDA, ${ }^{50,51}$ and GLY was approved by EMA $^{52}$ for use in stable COPD. The efficacy of QVA149 (50 $\mu \mathrm{g}$ DPI once daily) has been reported in a series of Phase III clinical trials under the IGNITE (Indacaterol and GlycopyrroNium bromide ClInical sTudiEs) program funded by Novartis Pharmaceuticals. The findings of the studies are summarized in Table 3.

Safety and efficacy of QVA149 were tested in the ENLIGHTEN trial, a 52-week randomized, PCBO-controlled trial in patients with moderate-to-severe COPD. ${ }^{53}$ At 52 weeks trough $\mathrm{FEV}_{1}$ was increased $189 \mathrm{~mL}$ with QVA149 vs PCBO $(P<0.001)$, rescue SABA use was reduced, and some symptom scores were improved with QVA149. Overall, the incidence of AEs was similar between groups. Numerically, more serious adverse events occurred in the QVA149 group; however, it did not meet statistical significance $(P=0.07)$. At baseline, the group given QVA149 had more severe COPD, 
more comorbidities (diabetes, myocardial infarction, and stroke), and a greater frequency of ICS prescription. The authors proposed that the numerical difference in AEs may be due to issues with group matching rather than effects of QVA149.

In the SHINE study, the efficacy of QVA149 was tested against its components, indacaterol $150 \mu \mathrm{g}$, GLY $50 \mu \mathrm{g}$, as well as TIO $18 \mu \mathrm{g}$ HandiHaler (Boehringer Ingelheim Pharmaceuticals, Inc., Ridgefield, CT, USA), and PCBO in a 26-week trial of over 2,100 patients with moderate-to-severe COPD.${ }^{54}$ QVA149 caused a rapid increase in $\mathrm{FEV}_{1}>100 \mathrm{~mL}$ at 5 minutes after the first dose. Trough $\mathrm{FEV}_{1}$ was increased for QVA149 vs all comparators, but vs active treatments, the FEV improvements were 70-90 $\mathrm{mL}$, approaching, but less than, accepted MCID for single agents. The proportion of patients who achieved a transition dyspnea index (TDI) score $\geq 1$ was greater for QVA149 than PCBO and TIO, and the proportion of responders for St George Respiratory Questionnaire (SGRQ) improvements $\geq 8$ was greater with QVA149 than PCBO, TIO, and GLY. ${ }^{55}$ Safety was similar in each group.

In the SPARK study, Wedzicha et $\mathrm{al}^{56}$ described the effect of QVA149 on exacerbation frequency in a group of patients with an $\mathrm{FEV}_{1}<50 \%$ and at least one exacerbation in the last year, approximately $75 \%$ of the included patients were prescribed ICS at baseline. Exacerbations were stratified as mild (self-managed at home), moderate (required corticosteroids and/or antibiotics), or severe (required hospitalization or an emergency room visit $>24$ hours). QVA149 reduced all exacerbations $14 \%$ vs TIO $(P=0.0017)$ and $15 \%$ vs GLY $(P=0.012)$. Moderate and severe exacerbations were decreased by $12 \%$ QVA149 vs GLY $(P=0.038)$, but the rate of moderate-to-severe AECOPD in the QVA149 group was not different than the TIO group. Compared to TIO and GLY, treatment with QVA149 improved health status for most of the 64-week trial.

In the ILLUMINATE trial, the effect of QVA149 vs salmeterol/fluticasone (SFC) $(50 / 500 \mu \mathrm{g})$ was studied in patients with moderate-to-severe COPD without exacerbations in the past year. ${ }^{57}$ At week $26, \mathrm{FEV}_{1} \mathrm{AUC}_{0-12 \mathrm{~h}}$ was improved by $138 \mathrm{~mL}$ in the QVA149 group vs $\mathrm{SFC}(P<0.0001)$, with similar benefits in terms of $\mathrm{FEV}_{1}$ at 5 and 30 minutes post dose, FVC peak, trough, and $\mathrm{AUC}_{0-12 \mathrm{~h}}$. The mean scores for SGRQ were similar, and the TDI improved 0.76 units in the QVA149 group, less than the MCID. Responder analysis showed that $67.5 \%$ of the QVA 149 group vs $56.8 \%$ of the SFC reported an improved TDI $\geq 1$, for an odds ratio (OR) of $1.51(P=0.046)$. Use of SABA was reduced by $0.39 \mathrm{puffs} /$ day $(P=0.019)$. There were no significant differences in AEs. In contrast to the GOLD recommendations, patients without a history of AECOPD are frequently documented to be prescribed ICS, ${ }^{58-60}$ which would arguably increase cost and risk without sufficient likelihood of benefit in most cases. ILLUMINATE provides assurance that in similar patients, changing from ICS/LABA to LAMA/LABA would be safe and may improve control of symptoms. The study was not designed to assess the impact of this intervention on exacerbations.

QVA149 was compared to the free combination of TIO plus FOR in the QUANTIFY study, a Phase III trial of over 900 patients in Germany with moderate-to-severe COPD. QVA149 was noninferior in terms of exacerbations, QOL, and mean dyspnea scores. ${ }^{61}$ Using responder analysis, dyspnea was improved with QVA149 (TDI $\geq 1$ QVA149 49.6\% vs TIO/FOR 42.4\%, $P=0.033$ ). In addition, QVA149 significantly improved predose $\mathrm{FEV}_{1}(68-72 \mathrm{~mL})$ and FVC (74-106 mL) at weeks 12 and 26 when compared to $\mathrm{TIO}+\mathrm{FOR}(P<0.05$ for both $)$, postdose $\mathrm{FEV}_{1}$ and $\mathrm{FVC}$ were similar. ${ }^{62}$

Dyspnea was the primary endpoint in the BLAZE study, a 3-period crossover study comparing QVA149, PCBO, and TIO. In the QVA149 group, dyspnea was improved with an OR for response by TDI of 1.78 vs TIO and 2.78 vs PCBO $\left(P<0.005\right.$ for both). Additionally, $\mathrm{FEV}_{1}, \mathrm{FVC}$, and rescue medication use were improved in the QVA149 group with similar safety outcomes. ${ }^{63}$

QVA149 has been shown to improve lung function, improve HRQOL and dyspnea, and, compared to TIO, reduce unreported exacerbations. It has been approved in Europe, Japan, Canada, and Latin America at a daily dose of $110 / 50 \mu \mathrm{g}$ once daily. The EXPEDITION (FLIGHT 1, 2 , and 3) studies have been recently completed at a dose of QVA149 27.5/12.5 $\mu \mathrm{g}$ twice daily, a dose which has been submitted to the FDA for approval. The results are not currently reported. ${ }^{51}$

\section{Aclidinium/formoterol}

ACL, a novel muscarinic antagonist, has been combined with formoterol fumarate in a DPI device. The time required for dissociation of ACL from M3 receptors is between that of $\mathrm{TIO}$ and ipratropium, and it is dosed twice daily. Interestingly, ACL is inactivated in plasma by hydrolysis, potentially decreasing side effects. ${ }^{22}$ The majority of published data is from two 24-week randomized, PCBO-controlled studies, AUGMENT COPD and ACLIFORM COPD. ${ }^{64,65}$ The drugs tested include twice-daily inhalation of aclidinium/formoterol (ACF) 400/12 $\mu \mathrm{g}$ (ACF12), ACF 400/6 $\mu \mathrm{g}$ (ACF6), FOR $12 \mu \mathrm{g}$, ACL $400 \mu \mathrm{g}$, and PCBO. 
The ACLIFORM study ${ }^{65}$ compared ACF12, ACF6, ACL, FOR, or PCBO in 1,729 patients with stable moderate-tosevere COPD. Both ACF12 and ACF6 increased trough and postdose $\mathrm{FEV}_{1}$, the higher dose preparation was generally more effective in bronchodilation. Curiously, the PCBO group experienced improvements in dyspnea and HRQOL above the MCID. Despite this, both ACF groups had a greater improvement in dyspnea and COPD symptoms compared to PCBO. HRQOL improved for all treatment groups (including $\mathrm{PCBO}$ ) beyond the MCID, ranging -6.5 points for $\mathrm{PCBO}$ and -7.2 to -8.3 for the ACF12 and ACF6, respectively. Unreported exacerbations were reduced compared to $\mathrm{PCBO}$ in the ACF12 group (rate ratio $0.71, P \leq 0.05$ ), but AECOPD resulting in changes in management occurred infrequently and did not differ between groups. AEs were similar between groups, and no deaths were attributed to the study drug.

In AUGMENT COPD, dyspnea was improved in both doses of ACF vs PCBO (TDI >1), HRQOL was improved $>$ MCID in the higher dose of ACF and in the ACL monotherapy group. ${ }^{66}$ In an extension of the AUGMENT trial, both doses of ACF were found to have a similar safety to PCBO over 1 year. Furthermore, combining the ACLIFORM and AUGMENT studies (total $\mathrm{N}=3,398$ ) over 6 months showed that cardiovascular events in both doses of ACF were similar to PCBO. ${ }^{67}$

One could conclude that ACF 400/12 $\mu \mathrm{g}$ inhaled twice daily increases $\mathrm{FEV}_{1}$ compared to $\mathrm{PCBO}$, and improves dyspnea and HRQOL. The above studies show a decrease in unreported exacerbations compared to PCBO in the groups treated with ACF. Treatment appears to be safe. One could take advantage of twice-daily dosing in reducing nocturnal dyspnea, although this has not been specifically described to our knowledge for ACF.

\section{Tiotropium/olodaterol}

$\mathrm{TIO} /$ olodaterol $(\mathrm{T} / \mathrm{O})$ is the most recently approved LAMA/ LABA garnering approval by the FDA in May of $2015 .{ }^{68}$ It is delivered in the Respimat ${ }^{\circledR}$ Soft Mist Inhaler (Boehringer Ingelheim Pharmaceuticals, Inc.), which has been shown to provide good drug delivery over a wide range of flows. In a 6-week crossover study of GOLD 2-4 COPD, T/O (5/5 and $2.5 / 5 \mu$ g once daily) increased $\mathrm{FEV}_{1}$ (trough, 24-hour AUC), functional residual capacity, and decreased residual volume compared to monocomponents and PCBO.${ }^{69}$ The magnitude of the effect on trough $\mathrm{FEV}_{1}$ benefit vs components $(79-107 \mathrm{~mL})$ was near or exceeded the MCID (all data not shown).

In a combined analysis of two replicate trials (TOnado 1 and 2), TIO and olodaterol were compared at two doses $\mathrm{TIO}+$ olodaterol $(\mathrm{T} / \mathrm{O} 5 / 5$ or $\mathrm{T} / \mathrm{O} 2.5 / 5 \mu \mathrm{g})$ to monocomponents olodaterol $5 \mu \mathrm{g}$, TIO 2.5 or $5 \mu \mathrm{g}$ over 52 weeks in patients with moderate to very severe COPD. ${ }^{70}$ Primary analysis at 24 weeks showed that both doses improved lung function $\left(\mathrm{FEV}_{1} \mathrm{AUC}_{0-3}\right.$, trough $\left.\mathrm{FEV}_{1}\right)$ compared to monocomponents. Although improvements in trough $\mathrm{FEV}_{1}$ reached statistical significance, the differences were modest, ranging from 38 to $85 \mathrm{~mL}$. QOL was improved by responder analysis of SGRQ. Dyspnea was improved in all groups (TDI focal score, 1.56-1.98), with statistical differences of the combination treatment over components, but differences between combination and component treatments were uniformly $<1$ unit. The study was not powered for exacerbations, but there was a trend toward reduced moderate-to-severe AECOPD in the combination group. The combination of TIO and olodaterol was found to have similar safety compared to monocomponents and did not differ between doses of TIO and olodaterol.

\section{Glycopyrronium/formoterol}

Glycopyrronium/formoterol (GFF) is a LAMA/LABA administered twice daily by metered dose inhaler (MDI). Two abstracts have been reported describing a 7-day Phase IIb trial comparing GFF 72/9.6 $\mu \mathrm{g}$ and GFF 36/9.6 $\mu \mathrm{g}$ to glycopyrrolate $36 \mu \mathrm{g}$ MDI, FOR 9.6 $\mu \mathrm{g}$ MDI, FOR $7.2 \mu \mathrm{g}$ MDI, TIO $18 \mu \mathrm{g}$ DPI, FOR $12 \mu \mathrm{g}$ DPI, and PCBO in 118 patients with moderate to very severe COPD. Compared to all other agents and $\mathrm{PCBO}, \mathrm{GFF} 72 / 9.6 \mu \mathrm{g}$ produced greater $\mathrm{FEV}_{1} \mathrm{AUC}_{0-12 \mathrm{~h}}$ on day 7, improving $103 \mathrm{~mL}$ vs TIO. This is important as GFF 72/9.6 $\mu \mathrm{g}$ compared favorably to both TIO and the monocomponents. GFF 36/9.6 $\mu \mathrm{g}$ was noninferior to the higher dose GFF 72/9.6 $\mu \mathrm{g}$. Peak and trough FEV, were improved in both doses of GFF (data not available). ${ }^{71}$ Both doses of GFF improved trough inspiratory capacity (90-105 mL) compared to TIO. ${ }^{71}$ The most frequent AE was dry mouth, similar to TIO. This agent is in Phase III development by Pearl Therapeutics (Durham, NC, USA).

\section{Bronchodilator activity and frequency of exacerbations}

Currently approved bronchodilators shown to reduce COPD exacerbations include TIO, aclidinium bromide, salmeterol, SFC, and budesonide/formoterol. ${ }^{18,72}$ Information regarding relative efficacy of these agents is limited. The largest trial, POET-COPD, found that TIO was more effective than salmeterol in preventing COPD exacerbations. ${ }^{73}$ In a 2-year trial, no difference in exacerbation rate was shown when TIO was compared to SFC. ${ }^{74}$ Agents in development would optimally prove superior to these agents at a lower cost with increased 
safety, while yielding other benefits such as improvement in dyspnea and HRQOL. Exacerbation frequency has been reported for QVA149, UMEC/VI, and ACF. In pooled data from two prospective 24-week studies (AUGMENT and ACLIFORM), ACF 400/12 $\mu \mathrm{g}$ dosed twice daily was noted to reduce COPD exacerbations rates by $0.70-0.79$ vs PCBO. ${ }^{75}$

The SPARK trial compared QVA149 to GLY $50 \mu \mathrm{g}$ or TIO $18 \mu \mathrm{g}$ HandiHaler in 2,224 patients, with a mean FEV of $37 \%$ and at least one exacerbation in the prior year. The primary outcome was COPD exacerbations, and the study was planned for 64 weeks, but was extended to 74 weeks to increase exacerbation events, which were lower than expected. QVA149 reduced all exacerbation rates compared to both GLY (reduced 15\%, $P=0.012$ ) and TIO (reduced 14\%, $P=0.0017$ ). Compared to TIO, QVA149 achieved statistically significant reductions only in mild exacerbations, defined as being self-managed at home without steroids or antibiotics. QVA149 reduced moderate or severe exacerbation rate compared to GLY. ${ }^{56}$ Interestingly, unreported AECOPD are both frequent and negatively impact health status. ${ }^{76}$

There are conflicting results regarding the prevention of AECOPD by using UMEC/VI. In a 24-week trial comparing UMEC/VI $62.5 / 25 \mu \mathrm{g}$ to $\mathrm{PCBO}$ and components, the hazard ratio for time to first COPD exacerbation was $0.5(P \leq 0.01)$ vs PCBO ${ }^{43}$ In a second 52-week trial comparing UMEC/VI $125 / 25 \mu \mathrm{g}$ to UMEC $125 \mu \mathrm{g}$ or PCBO, hospitalizations were reduced in both treatment groups $(6 \%-7 \%)$ vs $\mathrm{PCBO}(12 \%)$. Although this is an important finding, the authors note that the aforementioned studies were not designed to study this outcome. ${ }^{46}$ In a trial of 1,493 patients with a mean $\mathrm{FEV}_{1}$ of $55 \%$, UMEC/VI 125/25 $\mu \mathrm{g}$ was compared to components UMEC $125 \mu \mathrm{g}$, VI $25 \mu \mathrm{g}$, and PCBO. Compared to PCBO, all treatments reduced the risk of AECOPD (HR: 0.4-0.5, $P \leq 0.006$ for all vs $\mathrm{PCBO}) .{ }^{47} \mathrm{COPD}$ exacerbations were defined as acute worsening, requiring emergency treatment beyond increasing home ALB. Finally, in two paired 24-week trials totaling 1,718 patients with a mean $\mathrm{FEV}_{1}$ of $47 \%-48 \%$, there were no differences in the time to first AECOPD between groups treated with UMEC/VI 125/25 $\mu \mathrm{g}$, UMEC/VI 62.5/ $25 \mu \mathrm{g}$, TIO $18 \mu \mathrm{g}$, VI $25 \mu \mathrm{g}$, or UMEC $125 \mu \mathrm{g}{ }^{44}$ The available evidence suggests that UMEC/VI 125/25 $\mu \mathrm{g}$ prevents AECOPD compared to PCBO, and UMEC/VI 62.5/25 $\mu$ g may prevent AECOPD compared to $\mathrm{PCBO}$. The reader is reminded that the approved doses are at or less than the latter.

\section{Prospects, real world evidence}

In 2013, best selling drugs included SFC at second place and TIO at 12 th. ${ }^{77}$ ICS/LABAs are frequently prescribed to patients at low risk for exacerbation, $18 \%$ of GOLD group B patients were prescribed ICS/LABA in one questionnaire. ${ }^{78}$ The combination of LAMA/LABA may provide an alternate combination medication to optimize therapeutic goals and avoid the risks and costs of ICS. In the recently published WISDOM trial comparing ICS + LABA + LAMA, vs stepdown to LAMA/LABA alone, noninferiority was demonstrated for the outcome of COPD exacerbations. ${ }^{79}$ In the future, identification of COPD phenotypes may allow clinicians to personalize bronchodilator prescription.

TIO has occupied the center stage for the management of COPD for the last decade. Presumably, the appeal of new agents for patients will be improvement in symptoms, reduced cost, and increased convenience. For physicians, reductions in AECOPD and adherence are likely to be important factors as well. In the SHINE study, QVA149 produced a rapid onset of bronchodilation, improved dyspnea, and QOL compared to PCBO and TIO. ${ }^{54}$ Although UMEC/VI 125/25 $\mu$ g improved $\mathrm{FEV}_{1}$, patient symptoms (dyspnea and HRQOL) did not improve compared to TIO alone. ${ }^{44}$ In TOnado, the combination of T/O improved dyspnea compared to TIO. ${ }^{80}$

Efficacy is a moot issue without adherence, a significant problem in COPD treatment. ${ }^{81}$ Generally, adherence increases with a simpler dosing regimen (once daily $>$ multiple times, single inhaler vs multiple) and in the presence of immediate symptom relief. In addition, ease of device use is an important factor, in one study, over $40 \%$ of the patients hospitalized failed at least one element of inhaler technique. ${ }^{82}$ Effective use of any inhaled medication depends on patient and physician education regarding proper technique, proper counseling, and follow-up with the patient. Combining bronchodilators streamlines the number of medications and dosing frequency the patient must recall, understand, and schedule into their daily routine and has the potential to limit toxicity through the use of lower dosages of both.

\section{New directions \\ Devices}

Novel devices are developed for inhaled bronchodilators in COPD; agents can be given individually as free inhalers or combined with another agent in a fixed-drug combination (FDC). All of the new therapies will be available in FDCs. There are some nuances in use of inhaler devices, in order to effectively and safely deliver therapy directly to the lung. Also, drug/drug interactions in new FDCs are carefully studied as the combinations are compared to the free drug inhalers by themselves. Many novel devices such as Ellipta ${ }^{\circledR}$ (GlaxoSmithKline plc, Durham, NC, USA) have been developed, and each type of device has its own advantages and perhaps a few have disadvantages. A pressurized MDI, with a cosuspension of GFF, 
a new upcoming FDC, is in the final stages of clinical trials at the present time. Others, such as the combination of T/O, will be in a soft mist device $\left(\right.$ Respimat $\left.^{\circledR}\right)$, while most others are in DPIs. The most important aspect is tailoring the device to the patients' physical condition, needs, and preferences.

\section{MABAs and triples}

One exciting development in the dual bronchodilator story is the potential use of dual agents or bifunctional muscarinic antagonists and $\beta_{2}$-agonists (MABAs) that are single molecule antimuscarinic and adrenergic agents. Clinical trials have established the efficacy and safety of these novel agents, and clinical development is progressing. MABAs may provide a pathway for triple therapy (provided by these agents) by adding an ICS. Also, the Ellipta ${ }^{\circledR}$ device is being tested with UMEC and the ICS/LABA fluticasone furoate and VI. Initial studies show additional bronchodilation with the triple combination, and the exacerbation results are pending. The WISDOM study however shows that one can do the opposite safely, reduce from triple to dual therapy without increasing exacerbations. ${ }^{79}$

\section{Nebulizer combinations}

One exciting area in research is the use of combinations in nebulizers for patients with COPD. Nebulizers enable higher doses of drugs to be used. Also, the nebulized aerosol may be delivered with a mask, which can be easier for older and weaker patients to use. Patients who are impaired, as well as those with low inspiratory flows, may also benefit from the nebulizers. New ultrasonic devices are being evaluated that will be more efficient than older devices. Presently, combinations of 12-hour LABAs such as FOR and arformoterol are being tested with LAMAs such as GLY and novel LAMAs. Previous studies of LAMA/LABAs using separate devices showed added improvement. These combinations, if effective and safe, will be very convenient for patients to use; one of the disadvantages with nebulizers was the long time needed to complete nebulization of two free drugs. Also, new combinations may include novel agents like anti-inflammatory drugs or mucolytics combined with bronchodilators. For example, agents that have side effects when given orally, such as phosphodiesterase- 4 inhibitors, may be combined in an inhaled form within an inhaled $\beta$-agonist. The inhaled $\beta$-agonist may offset some of the acute effects of nonbronchodilators, transiently reducing $\mathrm{FEV}_{1}$.

\section{Conclusion}

The addition of LAMA/LABA in a single inhaler device offers a significant new approach to therapy. There is clear evidence that patients with COPD are excessively prescribed ICS/LABA combinations. Emerging evidence that stopping ICS is safe for some patients further assures the clinician that treatment with a LAMA/LABA would be reasonable. Patients with dyspnea despite the use of either a LAMA or LABA may have improvement in HRQOL, dyspnea, and reduced rescue medication use with LAMA/LABA. Additionally, some agents have reported improvement in exacerbations. Similar to the Goldilocks principle, we search for therapies that are "just right" for the individual patient. With the addition of LAMA/LABA, there are now more bowls at the table.

\section{Disclosure}

JFD is a consultant for AZ, BI, GSK, Mylan, Novartis, and Sunovion, and JAO is on the advisory boards of BI, AZ, CSL Behring, and Novartis. The authors report no other conflicts of interest in this work.

\section{References}

1. Mathers CD, Loncar D. Projections of global mortality and burden of disease from 2002 to 2030. PLoS Med. 2006;3(11):e442.

2. Diaz-Guzman E, Mannino DM. Epidemiology and prevalence of chronic obstructive pulmonary disease. Clin Chest Med. 2014;35(1):7-16.

3. Hogg JC, Timens W. The pathology of chronic obstructive pulmonary disease. Annu Rev Pathol. 2009;4:435-459.

4. Salvi SS, Barnes PJ. Chronic obstructive pulmonary disease in nonsmokers. Lancet. 2009;374(9691):733-743.

5. Ohar J, Sterling DA, Bleecker E, Donohue J. Changing patterns in asbestos-induced lung disease. Chest. 2004;125(2):744-753.

6. McDonough JE, Yuan R, Suzuki M, et al. Small-airway obstruction and emphysema in chronic obstructive pulmonary disease. NEnglJMed.2011; 365(17):1567-1575.

7. Senior R, Atkinson J. Chronic obstructive pulmonary disease: epidemiology, pathophysiology, and pathogenesis. In: Alfred Fishman M, editor. Fishman's Pulmonary Diseases and Disorders. Vol. 1. 4th ed. New York, NY: McGraw Hill Medical; 2008:707-728.

8. O'Donnell DE, Laveneziana P. Physiology and consequences of lung hyperinflation in COPD. Eur Respir Rev. 2006;15(100):61-67.

9. Casanova C, Cote C, de Torres JP, et al. Inspiratory-to-total lung capacity ratio predicts mortality in patients with chronic obstructive pulmonary disease. Am J Respir Crit Care Med. 2005;171(6):591-597.

10. O'Donnell DE, Fluge T, Gerken F, et al. Effects of tiotropium on lung hyperinflation, dyspnoea and exercise tolerance in COPD. Eur Respir J. 2004;23(6):832-840.

11. The Global Strategy for the Diagnosis, Management, and Prevention of COPD, Global Initiative for Chronic Obstructive Lung Disease (GOLD). 2015. Available from: http://www.goldcopd.org. Accessed March 8, 2015.

12. Qaseem A, Wilt TJ, Weinberger SE, et al. Diagnosis and management of stable chronic obstructive pulmonary disease: a clinical practice guideline update from the American College of Physicians, American College of Chest Physicians, American Thoracic Society, and European Respiratory Society. Ann Intern Med. 2011;155(3):179-191.

13. Seemungal TA, Donaldson GC, Paul EA, Bestall JC, Jeffries DJ, Wedzicha JA. Effect of exacerbation on quality of life in patients with chronic obstructive pulmonary disease. Am J Respir Crit Care Med. 1998; 157(5 Pt 1):1418-1422.

14. Vestbo J, Edwards LD, Scanlon PD, et al. Changes in forced expiratory volume in 1 second over time in COPD. $N$ Engl $J$ Med. 2011;365(13):1184-1192. 
15. Singanayagam A, Schembri S, Chalmers JD. Predictors of mortality in hospitalized adults with acute exacerbation of chronic obstructive pulmonary disease. Ann Am Thorac Soc. 2013;10(2):81-89.

16. Soler-Cataluna JJ, Martinez-Garcia MA, Roman Sanchez P, Salcedo E, Navarro M, Ochando R. Severe acute exacerbations and mortality in patients with chronic obstructive pulmonary disease. Thorax. 2005; 60(11):925-931.

17. Hurst JR, Vestbo J, Anzueto A, et al. Susceptibility to exacerbation in chronic obstructive pulmonary disease. $N$ Engl J Med. 2010;363(12): 1128-1138.

18. Marchetti N, Criner GJ, Albert RK. Preventing acute exacerbations and hospital admissions in COPD. Chest. 2013;143(5):1444-1454.

19. Ohar JA, Sadeghnejad A, Meyers DA, Donohue JF, Bleecker ER. Do symptoms predict COPD in smokers? Chest. 2010;137(6):1345-1353.

20. Buist AS, McBurnie MA, Vollmer WM, et al. International variation in the prevalence of COPD (the BOLD Study): a population-based prevalence study. Lancet. 2007;370(9589):741-750.

21. Vanfleteren LE, Spruit MA, Groenen M, et al. Clusters of comorbidities based on validated objective measurements and systemic inflammation in patients with chronic obstructive pulmonary disease. Am J Respir Crit Care Med. 2013;187(7):728-735.

22. Cazzola M, Page CP, Calzetta L, Matera MG. Pharmacology and therapeutics of bronchodilators. Pharmacol Rev. 2012;64(3):450-504.

23. Jackson M. "Divine stramonium": the rise and fall of smoking for asthma. Med Hist. 2010;54(2):171-194.

24. Bray GW. The treatment of asthma. Br Med J. 1935;1(3863):119-121.

25. U.S. Food and Drug Administration. Department of Health and Human Services. Tudorza Pressair (aclidinium bromide inhalation powder) approval letter. 2012. Available from: http://www.accessdata.fda.gov/ drugsatfda_docs/appletter/2012/202450Orig1s0001tr.pdf. Accessed November 22, 2014

26. U.S. Food and Drug Administration. Department of Health and Human Services. Incruse Ellipta (umeclidinium bromide inhalation powder) approval letter. 2014. Available from: http://www.accessdata.fda.gov/ drugsatfda_docs/appletter/2014/205382Orig1s0001tr.pdf. Accessed November 22, 2014

27. Miles MC, Donohue JF, Ohar JA. Combination therapy for COPD: emerging evidence from recent clinical trials. J Clin Invest. 2011;1(6): 879-890.

28. Cazzola M, MacNee W, Martinez FJ, et al. Outcomes for COPD pharmacological trials: from lung function to biomarkers. Eur Respir J. 2008; 31(2):416-469.

29. Jones PW, Beeh KM, Chapman KR, Decramer M, Mahler DA, Wedzicha JA. Minimal clinically important differences in pharmacological trials. Am J Respir Crit Care Med. 2014;189(3):250-255.

30. Leidy NK, Sexton CC, Jones PW, et al. Measuring respiratory symptoms in clinical trials of COPD: reliability and validity of a daily diary. Thorax. 2014;69(5):443-449.

31. Tashkin DP, Celli B, Senn S, et al. A 4-year trial of tiotropium in chronic obstructive pulmonary disease. $N$ Engl J Med. 2008;359(15):1543-1554.

32. Calverley PM, Anderson JA, Celli B, et al. Salmeterol and fluticasone propionate and survival in chronic obstructive pulmonary disease. N Engl J Med. 2007;356(8):775-789.

33. Calverley PM, Boonsawat W, Cseke Z, Zhong N, Peterson S, Olsson H. Maintenance therapy with budesonide and formoterol in chronic obstructive pulmonary disease. Eur Respir J. 2003;22(6):912-919.

34. Cazzola M, Molimard M. The scientific rationale for combining longacting beta2-agonists and muscarinic antagonists in COPD. Pulm Pharmacol Ther. 2010;23(4):257-267.

35. COMBIVENT Inhalation Aerosol Study Group. In chronic obstructive pulmonary disease, a combination of ipratropium and albuterol is more effective than either agent alone. An 85-day multicenter trial. COMBIVENT Inhalation Aerosol Study Group. Chest. 1994;105(5):1411-1419.

36. CIAS Group. Routine nebulized ipratropium and albuterol together are better than either alone in COPD. The COMBIVENT Inhalation Solution Study Group. Chest. 1997;112(6):1514-1521.
37. van Noord JA, Aumann JL, Janssens E, et al. Combining tiotropium and salmeterol in COPD: effects on airflow obstruction and symptoms. Respir Med. 2010;104(7):995-1004.

38. Donohue JF, Anzueto A, Brooks J, Mehta R, Kalberg C, Crater G. A randomized, double-blind dose-ranging study of the novel LAMA GSK573719 in patients with COPD. Respir Med. 2012;106(7):970-979.

39. Hanania NA, Feldman G, Zachgo W, et al. The efficacy and safety of the novel long-acting beta2 agonist vilanterol in patients with COPD: a randomized placebo-controlled trial. Chest. 2012;142(1): 119-127.

40. Anoro ${ }^{\mathrm{TM}}$ [prescribing information]. Durham, NC: GlaxoSmithKline plc; 2013. Available from: https://www.gsksource.com/pharma/content/ dam/GlaxoSmithKline/US/en/Prescribing_Information/Anoro_Ellipta/ pdf/ANORO-ELLIPTA-PI-MG.PDF. Accessed May 10, 2015.

41. Mahler DA, Kerwin E, Ayers T, et al. FLIGHT: efficacy and safety of QVA149 (indacaterol/glycopyrrolate) versus its monocomponents and placebo in patients with COPD. Am J Respir Crit Care Med. Epub July 15, 2015.

42. Feldman G, Walker RR, Brooks J, Mehta R, Crater G. 28-Day safety and tolerability of umeclidinium in combination with vilanterol in COPD: a randomized placebo-controlled trial. Pulm Pharmacol Ther. 2012;25(6):465-471.

43. Donohue JF, Maleki-Yazdi MR, Kilbride S, Mehta R, Kalberg C, Church A. Efficacy and safety of once-daily umeclidinium/vilanterol 62.5/25 mcg in COPD. Respir Med. 2013;107(10):1538-1546.

44. Decramer M, Anzueto A, Kerwin E, et al. Efficacy and safety of umeclidinium plus vilanterol versus tiotropium, vilanterol, or umeclidinium monotherapies over 24 weeks in patients with chronic obstructive pulmonary disease: results from two multicentre, blinded, randomised controlled trials. Lancet Respir Med. 2014;2(6): $472-486$.

45. Sin DD. Wanted: new treatments for COPD. Lancet Respir Med. 2014; 2(6):434-436

46. Donohue JF, Niewoehner D, Brooks J, O'Dell D, Church A. Safety and tolerability of once-daily umeclidinium/vilanterol 125/25 mcg and umeclidinium $125 \mathrm{mcg}$ in patients with chronic obstructive pulmonary disease: results from a 52-week, randomized, double-blind, placebocontrolled study. Respir Res. 2014;15(1):78.

47. Celli B, Crater G, Kilbride S, et al. Once-daily umeclidinium/vilanterol 125/25 $\mu \mathrm{g}$ therapy in COPD: a randomized, controlled study. Chest. 2014; 145(5):981-991.

48. CHMP - Committee for Medicinal Products for Human Use. Initial authorisation of Ultibro Breezhaler (indacaterol/glycopyrronium bromide). 2013. Available from: http://www.ema.europa.eu/docs/en_GB/ document_library/Summary_of_opinion_-_Initial_authorisation/ human/002679/WC500146589.pdf. Accessed August 12, 2014.

49. Novartis. Novartis announces robust Phase III results for QVA149 and NVA237 and submits regulatory applications to US FDA. 2015. Available from: https:/www.novartis.com/news/media-releases/novartisannounces-robust-phase-iii-results-qva149-and-nva237-and-submits. Accessed January 29, 2015.

50. European Medicines Agency. Summary of positive opinion for Onbrez Breezhaler (indacaterol maleate). 2009. Available from: http://www. ema.europa.eu/docs/en_GB/document_library/Summary_of_opinion_-_Initial_authorisation/human/001114/WC500059632.pdf. Accessed August 12, 2014.

51. FDA. Indacaterol FDA approval information. Available from: http://www.accessdata.fda.gov/scripts/cder/drugsatfda/index.cfm? fuseaction=Search.DrugDetails. Accessed August 12, 2014.

52. European Medicines Agency. Initial authorisation Seebri Breezhaler (glycopyrronium bromide). 2012. Available from: http:// www.ema.europa.eu/docs/en_GB/document_library/Summary_ of_opinion_-_Initial_authorisation/human/002430/WC500129033.pdf. Accessed August 12, 2014.

53. Dahl R, Chapman KR, Rudolf M, et al. Safety and efficacy of dual bronchodilation with QVA149 in COPD patients: the ENLIGHTEN study. Respir Med. 2013;107(10):1558-1567. 
54. Bateman ED, Ferguson GT, Barnes N, et al. Dual bronchodilation with QVA149 versus single bronchodilator therapy: the SHINE study. Eur Respir J. 2013;42(6):1484-1494.

55. Bateman ED, Ferguson GT, Barnes N, et al. Dual bronchodilation with QVA149 versus single bronchodilator therapy: the SHINE study (Supplementary Material). 2013. Available from: http://www.erj.ersjournals. com/content/suppl/2013/09/03/09031936.00200212.DC1/erj020022012_online_supplementary_material.pdf. Accessed August 12, 2014.

56. Wedzicha JA, Decramer M, Ficker JH, et al. Analysis of chronic obstructive pulmonary disease exacerbations with the dual bronchodilator QVA149 compared with glycopyrronium and tiotropium (SPARK): a randomised, double-blind, parallel-group study. Lancet Respir Med. 2013; 1(3):199-209.

57. Vogelmeier CF, Bateman ED, Pallante J, et al. Efficacy and safety of once-daily QVA149 compared with twice-daily salmeterol-fluticasone in patients with chronic obstructive pulmonary disease (ILLUMINATE): a randomised, double-blind, parallel group study. Lancet Respir Med.2013; 1(1):51-60.

58. Asche CV, Leader S, Plauschinat C, et al. Adherence to current guidelines for chronic obstructive pulmonary disease (COPD) among patients treated with combination of long-acting bronchodilators or inhaled corticosteroids. Int J Chron Obstruct Pulmon Dis. 2012;7:201-209.

59. Bourbeau J, Sebaldt RJ, Day A, et al. Practice patterns in the management of chronic obstructive pulmonary disease in primary practice: the CAGE study. Can Respir J. 2008;15(1):13-19.

60. White P, Thornton H, Pinnock H, Georgopoulou S, Booth HP. Overtreatment of COPD with inhaled corticosteroids-implications for safety and costs: cross-sectional observational study. PLoS One. 2013;8(10): e75221.

61. Korn S, Gebner C, Schurmann W, et al. Once daily QVA149 improves dyspnea, quality of life and reduces the rate of exacerbations compared to tiotropium plus formoterol in COPD patients: the quantify study. $\mathrm{Am}$ J Respir Crit Care Med. 2014;189:A5982.

62. Gebner C, Schurmann W, Forster K, et al. Once daily QVA149 demonstrates superior improvements in lung function compared to tiotropium plus formoterol: the quantify study. Am J Respir Crit Care Med. 2014; 189:A5983.

63. Mahler DA, Decramer M, D’Urzo A, et al. Dual bronchodilation with QVA149 reduces patient-reported dyspnoea in COPD: the BLAZE study. Eur Respir J. 2014;43(6):1599-1609.

64. D’Urzo A, Mergel V, Leselbaum A, Caracta C. Efficacy and safety of fixed-dose combination aclidinium bromide/formoterol fumarate in patients with COPD: results from the AUGMENT COPD trial. Chest. 2013;144(4_MeetingAbstracts):1025A.

65. Singh D, Jones PW, Bateman ED, et al. Efficacy and safety of aclidinium bromide/formoterol fumarate fixed-dose combinations compared with individual components and placebo in patients with COPD (ACLIFORMCOPD): a multicentre, randomised study. BMC Pulm Med. 2014;14:178.

66. Rennard S, D’Urzo A, Jones P, Mergel V, Leselbaum A, Caracta C. Fixed-dose combination of aclidinium bromide/formoterol fumarate improve breathlessness and health status in COPD patients: AUGMENT COPD trial. Am J Respir Crit Care Med. 2014;189:A6007.

67. Donohue JF, D’Urzo A, Singh D, et al. Cardiovascular safety of fixeddose combination aclidinium bromide/formoterol fumarate: results of two 6-month studies in patients with moderate to severe COPD. Am J Respir Crit Care Med. 2014;189:A6011.
68. U.S. Food and Drug Administration. Department of Health and Human Services. Stiolto Respimat (tiotropium bromide and olodaterol inhalation spray) approval letter. 2015. Available from: http://www. accessdata.fda.gov/drugsatfda_docs/appletter/2015/206756Orig1s00 01tr.pdf. Accessed July 30, 2015.

69. Derom E, Westerman J, Grönke L, Hamilton A, Li C, Beeh K. P258 the 24-hour lung function profile of once-daily tiotropium and olodaterol fixed-dose combination compared with placebo and monotherapies in chronic obstructive pulmonary disease. Thorax. 2014;69(Supp1 2): A190-A191.

70. Buhl R, Maltais F, Abrahams R, et al. Tiotropium and olodaterol fixeddose combination versus mono-components in COPD (GOLD 2-4). Eur Respir J. 2015;45(4):969-979.

71. Reisner C, St Rose E, Strom S, et al. Fixed combination of glycopyrrolate and formoterol MDI (GFF-MDI) demonstrates superior inspiratory capacity (IC) compared to tiotropium DPI (Tio) following 7 days dosing, in a randomized, double-blind, placebo-controlled phase $2 \mathrm{~b}$ study in patients with COPD. Eur Respir J. 2011;38(Suppl 55):879.

72. Jones PW, Singh D, Bateman ED, et al. Efficacy and safety of twicedaily aclidinium bromide in COPD patients: the ATTAIN study. Eur Respir J. 2012;40(4):830-836.

73. Vogelmeier C, Hederer B, Glaab T, et al. Tiotropium versus salmeterol for the prevention of exacerbations of COPD. $N$ Engl J Med. 2011; 364(12):1093-1103

74. Wedzicha JA, Calverley PM, Seemungal TA, Hagan G, Ansari Z, Stockley RA. The prevention of chronic obstructive pulmonary disease exacerbations by salmeterol/fluticasone propionate or tiotropium bromide. Am J Respir Crit Care Med. 2008;177(1):19-26.

75. Bateman E, Rennard S, Jones P, Molins E, Jin M, Leselbaum A. Effect of aclidinium bromide/formoterol fumarate fixed-dose combination (FDC) on exacerbations in moderate-to-severe COPD: pooled analysis of two studies. Eur Respir J. 2014;44(Suppl 58):285.

76. Jones PW, Lamarca R, Chuecos F, et al. Characterisation and impact of reported and unreported exacerbations: results from ATTAIN. Eur Respir J. 2014;44(5):1156-1165.

77. IMS Health MIDAS. Top 20 global products. 2013. Available from: http://www.imshealth.com/cds/imshealth/Global/Content/Corporate/ Press\%20Room/Global_2013/Top_20_Global_Products_2013.pdf Accessed January 1, 2014

78. Small M, Broomfield S, Higgins V. Quantification and treatment patterns of Real-World Patients Classified by the GOLD 2011 Strategy. Thorax. 2012;67(Suppl 2):A144-A145.

79. Magnussen H, Disse B, Rodriguez-Roisin R, et al. Withdrawal of inhaled glucocorticoids and exacerbations of COPD. $N$ Engl J Med. 2014; 371(14):1285-1294.

80. Buhl R, Derom E, Ferguson G, et al. Once-daily tiotropium and olodaterol fixed-dose combination via the Respimat ${ }^{\mathbb{R}}$ improves outcomes vs mono-components in COPD in two 1-year studies. Eur Respir J. 2014; 44(Suppl 58, OP1895).

81. Bourbeau J, Bartlett SJ. Patient adherence in COPD. Thorax. 2008;63(9): 831-838.

82. Garcia-Aymerich J, Barreiro E, Farrero E, Marrades RM, Morera J, Anto JM. Patients hospitalized for COPD have a high prevalence of modifiable risk factors for exacerbation (EFRAM study). Eur Respir J. 2000; 16(6):1037-1042.
International Journal of COPD

\section{Publish your work in this journal}

The International Journal of COPD is an international, peer-reviewed journal of therapeutics and pharmacology focusing on concise rapid reporting of clinical studies and reviews in COPD. Special focus is given to the pathophysiological processes underlying the disease, intervention programs, patient focused education, and self management protocols.

\section{Dovepress}

This journal is indexed on PubMed Central, MedLine and CAS. The manuscript management system is completely online and includes a very quick and fair peer-review system, which is all easy to use. Visi http://www.dovepress.com/testimonials.php to read real quotes from published authors. 